\author{
D) Check for updates \\ Cite this: Org. Chem. Front., 2019, 6 , \\ 1816
}

Received 8th March 2019, Accepted 2nd April 2019

DOI: $10.1039 / c 9 q 000343 f$

rsc.li/frontiers-organic

\title{
Rh(I)-Catalyzed intramolecular [3 + 2] cycloaddition reactions of yne-vinylidenecyclopropanes $\uparrow$
}

\author{
Kang-Hua Rui ${ }^{a}$ and Min Shi (D) *a,b,c
}

A cationic Rh(I) complex-catalyzed intramolecular [3 + 2] cycloaddition reaction of newly developed yne-vinylidenecyclopropanes (VDCPs) has been established, affording an efficient synthesis of fused [6.5]-bicyclic structures in moderate to good yields under mild conditions. Moreover, the reaction exhibits a broad substrate scope along with good functional group tolerance.

\section{Introduction}

Bicyclic ring structures widely exist in natural products and are essential skeletons ubiquitously contained in some biologically important compounds possessing various biological activities. ${ }^{1}$ Therefore, developing new methods to synthesize bicyclic scaffolds has been intensively pursued by the synthetic community. During the past few decades, rhodium-catalyzed $\mathrm{C}-\mathrm{C}$ bond activation reactions and cycloadditions have emerged as one of the most powerful and straightforward methods in terms of good atom economy and mild reaction conditions for the construction of complex polycyclic frameworks. ${ }^{2}$ Methylenecyclopropanes (MCPs), ${ }^{3,4}$ vinylcyclopropanes $(\mathrm{VCPs})^{5,6}$ and vinylidenecyclopropanes (VDCPs) ${ }^{7,8}$ as highly strained but readily accessible and adequately reactive molecules have been frequently used in the rapid construction of polycyclic skeletons since they are fascinating building blocks for organic synthesis. Recently, many interesting transformations have been explored using novel functionalized alkylidenecyclopropanes as substrates upon transition metal catalysis. These reactions can provide diversified polycyclic products with high chemo- and regioselectivities under mild conditions. Our research group has long been interested in discovering transition metal-catalyzed intramolecular cycloadditions of functionalized VDCPs for the construction of polycyclic frameworks. Previously, we reported an intramolecular $[2+2]$ cyclo-

\footnotetext{
${ }^{a}$ Key Laboratory for Advanced Materials and Institute of Fine Chemicals, School of Chemistry \& Molecular Engineering, East China University of Science and Technology, Meilong Road No. 130, Shanghai, 200237, China

${ }^{b}$ State Key Laboratory and Institute of Elemento-organic Chemistry, Nankai University, Tianjin 300071, P. R. China

${ }^{c}$ State Key Laboratory of Organometallic Chemistry, Center for Excellence in Molecular Synthesis, University of Chinese Academy of Science, Shanghai Institute of Organic Chemistry, Chinese Academy of Sciences, 345 Lingling Road,

Shanghai 200032, China.E-mail:mshi@mail.sioc.ac.cn

$\dagger$ Electronic supplementary information (ESI) available: Experimental procedures, characterization data of new compounds. See DOI: 10.1039/c9qo00343f
}

addition of yne-VDCPs I-1 for the production of cyclopropane containing polycyclic compounds (Scheme 1a). ${ }^{9}$ In this cycloaddition reaction, the coordination of the rhodium(I) complex to the internal double bond of the allene unit and the alkyne moiety formed intermediate $\mathbf{I I}-\mathbf{1}$, which subsequently underwent cyclometalation/reductive elimination to afford the corresponding polycyclic products IV-1. In 2012, a highly efficient $\mathrm{Rh}(\mathrm{I})$-catalyzed Pauson-Khand-type $[2+2+1]$ cycloaddition of ene-VDCPs I-2 with CO was achieved by our group (Scheme 1b). ${ }^{10}$ The reaction proceeded through a cyclometalation of $\mathbf{I}-2$ with a $\mathrm{Rh}(\mathrm{I})$ catalyst to give rhodacyclic intermediate II-2, which underwent the insertion of $\mathrm{CO}$ to provide two regioisomers, III-2 and IV-2. These reactive species underwent reductive elimination to afford the corresponding cyclopropane containing polycyclic adducts $\mathbf{V}-\mathbf{2}$ in good yields. In this context, we report a cationic $\mathrm{Rh}(\mathrm{I})$ complex-catalyzed intramolecular [3 + 2] cycloaddition of newly developed yne-VDCPs 1 to afford a variety of bicyclic derivatives 2 with good functional group tolerance under mild conditions. On the basis of previous work, we envisaged that the cyclometalation of the $\mathrm{Rh}$ catalyst with the alkyne group and the double bond adjacent to the VDCP moiety could initially give intermediate $\mathbf{I}-\mathbf{3}$, which would directly undergo a $\beta$-carbon elimination to form the corresponding $\pi$-allyl $\mathrm{Rh}$ (III) intermediate II-3. The subsequent reductive elimination of intermediate II-3 could give the desired bicyclic product 2 (Scheme 1c). In this intramolecular $[3+2]$ cycloaddition reaction, the cyclopropane could act as a three-carbon synthon to give the corresponding. ring-opened products rather than the cyclopropane ring retaining polycyclic products. It should be mentioned here that in 2014 we disclosed a gold(I)-catalyzed cycloisomerization of yne-VDCPs for the synthesis of bicyclic derivatives. ${ }^{8 j}$ However, these reactions underwent 5-exo-dig and 6-exo-dig cyclizations at the same time, giving bicyclic derivatives as well as VDCPrearranged products as product mixtures in most cases since gold(I) catalysts are the most powerful soft Lewis acids for electrophilic activation of $\mathrm{C}-\mathrm{C}$ triple bonds, rendering difficulties 
a) $\mathrm{Rh}(\mathrm{I})$-catalyzed [2+2] cycloaddition of Yne-VDCPs
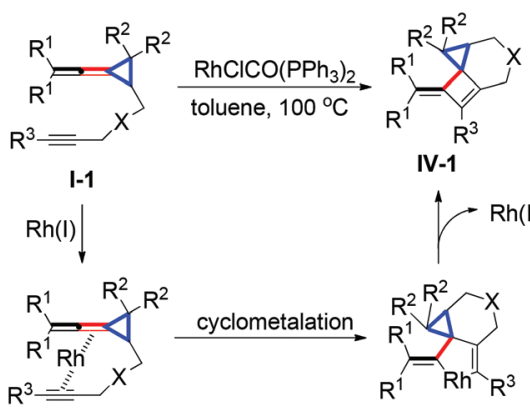

IV-1

II-1

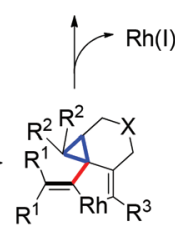

III-1

b) $\mathrm{Rh}(\mathrm{I})$-catalyzed Pauson-Khand Reaction of Ene-VDCPs
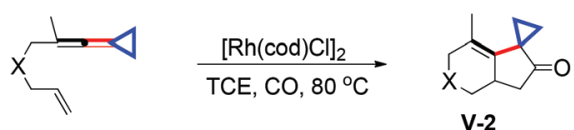

I-2

V-2

$\operatorname{Rh}(\mathrm{l}) \mid$ cyclometalation

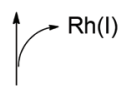

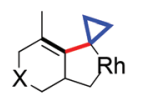

II-2

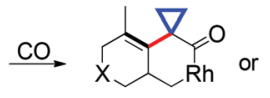

III-2

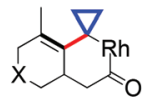

IV-2

c) This design<smiles>[X]C([R])C1CC1C1CC1</smiles>
$\left[\mathrm{Rh}(\mathrm{cod})_{2}\right] \mathrm{BF}_{4}(4 \mathrm{~mol} \%)$
$(\mathrm{rac})-\operatorname{Binap}(4 \mathrm{~mol} \%)$

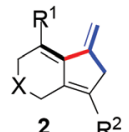

1<smiles>C[AsH2+]</smiles><smiles>CCC[Te][Te]</smiles>

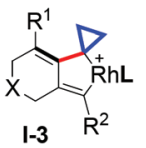
$\beta$-carbon elimination

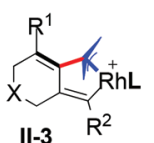

II-3 R
Scheme 1 Previous work and this work.

in the control of the regioselectivity. In addition, the gold-catalyzed reaction was limited to the use of terminal alkynes as substrates. On the other hand, rhodium(I) catalysts prefer to undergo oxidative addition in the reactions using ene-VDCPs or yne-VDCPs as substrates. Therefore, it is possible to overcome the shortage in the control of regioselectivity in the gold (I) catalyzed transformation and enable extension of the substrate scope and to afford bicyclic products exclusively if using a rhodium(I) complex as the catalyst.

\section{Results and discussion}

Our initial examination started with the tosylamide tethered yne-VDCP substrate 1a. Thus, a solution of 1a in 1,2-dichloroethane (DCE) was heated at $80{ }^{\circ} \mathrm{C}$ in the presence of $4 \mathrm{~mol} \%$ of $\left[\mathrm{Rh}(\mathrm{cod})_{2}\right] \mathrm{BF}_{4}$ and $4 \mathrm{~mol} \%$ of ( $\mathrm{rac}$ )-Binap. To our delight, the desired bicyclic product 2 a was exclusively produced in $45 \%$ yield (Table 1 , entry 1 ). With this encouraging result, we then
Table 1 Optimization of the reaction conditions

\begin{tabular}{|c|c|c|c|c|}
\hline & $\operatorname{Ts} \sqrt{\frac{1 a}{\equiv}}$ & $\begin{array}{l}\begin{array}{l}\text { catalyst }(4 \mathrm{~mol} \%) \\
\text { ligand }(4 \mathrm{~mol} \%)\end{array} \\
\text { Solvent, } 80^{\circ} \mathrm{C}\end{array}$ & $2 a$ & \\
\hline Entry $^{a}$ & Catalyst & Ligand & Solvent & Yield $^{b}[\%]$ \\
\hline 1 & {$\left[\mathrm{Rh}(\operatorname{cod})_{2}\right] \mathrm{BF}_{4}$} & $(r a c)$-Binap & DCE & 45 \\
\hline 2 & {$\left[\mathrm{Rh}(\operatorname{cod})_{2}\right] \mathrm{BF}_{4}$} & (rac)-Binap & Dioxane & 62 \\
\hline 3 & $\left.\mathrm{Rh}(\operatorname{cod})_{2}\right] \mathrm{BF}_{4}$ & (rac)-Binap & $\mathrm{CH}_{3} \mathrm{CN}$ & 21 \\
\hline 4 & {$\left[R h(\operatorname{cod})_{2}\right] B_{4}$} & (rac)-Binap & PhCl & 83 \\
\hline 5 & {$\left[\mathrm{Rh}(\operatorname{cod})_{2}\right] \mathrm{BF}_{4}$} & ${ }^{t}$ BuXPhos & $\mathrm{PhCl}$ & 48 \\
\hline 6 & {$\left[\mathrm{Rh}(\operatorname{cod})_{2}\right] \mathrm{BF}_{4}$} & dppe & $\mathrm{PhCl}$ & 68 \\
\hline 7 & {$\left[\mathrm{Rh}(\operatorname{cod})_{2}\right] \mathrm{BF}_{4}$} & dppf & $\mathrm{PhCl}$ & 61 \\
\hline 8 & {$\left[\mathrm{Rh}(\operatorname{cod})_{2}\right] \mathrm{BAr}_{\mathrm{F}}$} & (rac)-Binap & $\mathrm{PhCl}$ & 72 \\
\hline $9^{c}$ & {$\left[\mathrm{Rh}(\operatorname{cod})_{2}\right] \mathrm{BF}_{4}$} & (rac)-Binap & $\mathrm{PhCl}$ & 78 \\
\hline
\end{tabular}

${ }^{a}$ Reaction conditions: 1a $(0.1 \mathrm{mmol})$, catalyst (4 mol\%), ligand (4 mol\%), and solvent ( $2 \mathrm{~mL}$ ) were used; 6-10 h. ${ }^{b}$ Isolated yield. ${ }^{c}$ The reaction was conducted at $90{ }^{\circ} \mathrm{C}$.

focused our efforts on seeking out the optimal reaction conditions. Screening of solvents indicated that $\mathrm{PhCl}$ was the best choice, providing $2 \mathrm{a}$ in $83 \%$ yield (Table 1 , entries $1-4$ ). A subsequent survey of other phosphine ligands revealed that using (rac)-Binap as the ligand gave $\mathbf{2 a}$ in the highest yield (Table 1, entries 5-7). In addition, using $\mathrm{NaBAr}_{\mathrm{F}}$ as a coordinating anion afforded $\mathbf{2 a}$ in $72 \%$ yield under otherwise identical conditions and raising the reaction temperature to $90{ }^{\circ} \mathrm{C}$ did not give a better result (Table 1, entries 8-9).

With the optimal reaction conditions in hand, we next examined the scope of the substrates and the results are shown in Table 2. For yne-VDCPs $\mathbf{1 b}-\mathbf{1 e}$, in which $\mathrm{R}^{1}$ could be various primary or secondary alkyl groups, the desired products $\mathbf{2 b}-2 \mathbf{e}$ were given in good yields ranging from $68-88 \%$. The $\mathrm{R}^{1}$ group could also be a 1-butenyl or benzyl group, giving the corresponding products $2 \mathbf{f}$ and $2 \mathbf{g}$ in $72 \%$ and $78 \%$ yields, respectively. Moreover, with the substrates $\mathbf{1} \mathbf{h}-\mathbf{1} \mathbf{j}$, in which the yne and VDCP moieties are connected by BsN, oxygen atom

Table 2 Substrate scope of the intramolecular cycloaddition of yne-VDCPs $1^{a, b}$

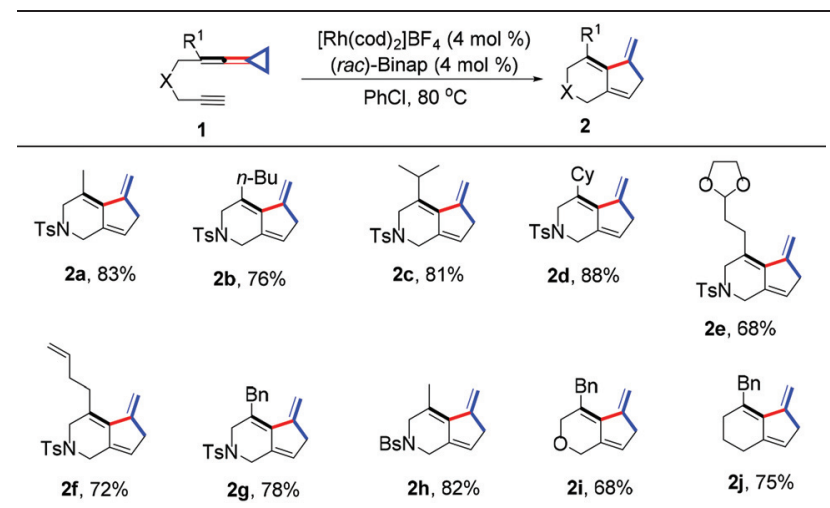

${ }^{a}$ Reaction conditions: yne-VDCP 1 ( $\left.0.10 \mathrm{mmol}\right), \quad\left[\mathrm{Rh}(\operatorname{cod})_{2}\right] \mathrm{BF}_{4}$ (4.0 mol\%), ( $\mathrm{rac}$ )-Binap (4.0 mol\%), and $\mathrm{PhCl}(2.0 \mathrm{~mL})$ were added and the reaction mixture was stirred for $6-8 \mathrm{~h} .{ }^{b}$ Isolated yield. 
and carbon anchor, the corresponding products $\mathbf{2 h}-\mathbf{2} \mathbf{j}$ were obtained in moderate to good yields as well.

Next, various substituents at the alkynyl moiety were explored (Table 3 ). When $\mathrm{R}^{2}$ was a methyl, pentyl or cyclohexyl group, the desired products $\mathbf{2} \mathbf{k}-\mathbf{2 m}$ were obtained in good to excellent yields. $\mathrm{R}^{2}$ could also be a benzyl group, giving the corresponding product $\mathbf{2 n}$ in $74 \%$ yield. For substrates 1o-1q, in which the alkyne moiety contained a primary or secondary acetoxyalkyl group, the desired products $\mathbf{2 0 - 2 q}$ were produced in good yields ranging from $81-86 \%$. In order to further explore the substrate scope of this protocol, substrates 1r and 1s, in which their alkynyl moieties have an olefinic group and an internal alkyne unit, were synthesized and the expected products $2 \mathbf{r}$ and 2 s were produced in $88 \%$ and $72 \%$ yields respectively under the standard conditions. Previously, we also reported a thermal induced intramolecular $[2+2]$ cycloaddition of alkynone-vinylidenecyclopropanes under heating conditions. ${ }^{11 a}$ Substrate 1t bearing an $\alpha, \beta$-unsaturated alkynyl ester was also tolerated, affording the desired product $2 \mathbf{t}$ in $76 \%$ yield. Notably, in this case, substrate $\mathbf{1 t}$ could be partially converted into a thermal-induced intramolecular $[2+2]$ cycloaddition byproduct $3 \mathbf{t}$ in $20 \%$ yield. ${ }^{11}$ Moreover, using $1 \mathbf{u}$ as the substrate, in which $\mathrm{R}^{2}=\mathrm{Ph}$, the desired product $2 \mathbf{u}$ was obtained in 58\% yield along with its thermal-induced $[2+2]$ cycloadduct $3 \mathbf{u}$ as a product mixture. Extending the carbon chain with a $\left(\mathrm{CH}_{2}\right)_{2}$ tether, the desired product $2 \mathbf{v}$ could be

Table 3 Substrate scope of the intramolecular cycloaddition of yne-VDCPs $1^{a, b}$

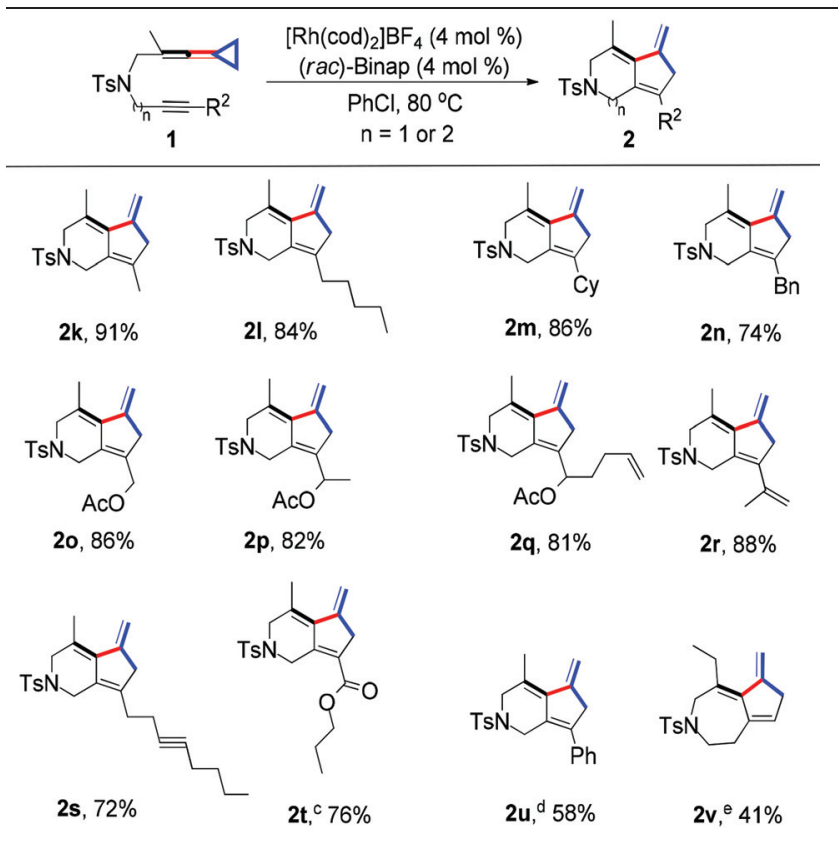

${ }^{a}$ Reaction conditions: yne-VDCP 1 (0.10 mmol), $\left[\mathrm{Rh}(\operatorname{cod})_{2}\right] \mathrm{BF}_{4}$ (4.0 $\mathrm{mol} \%)$, ( $\mathrm{rac}$ )-Binap (4.0 $\mathrm{mol} \%)$, and $\mathrm{PhCl}(2.0 \mathrm{~mL})$ were added and the reaction mixture was stirred for $6-8 \mathrm{~h} .{ }^{b}$ Isolated yield. ${ }^{c}$ Byproduct 3t was obtained in $20 \%$ yield (see Scheme 2 ). ${ }^{d}$ Byproduct $3 \mathbf{u}$ was obtained in $29 \%$ yield. ${ }^{e}$ DCE was employed as the solvent in place of PhCl.
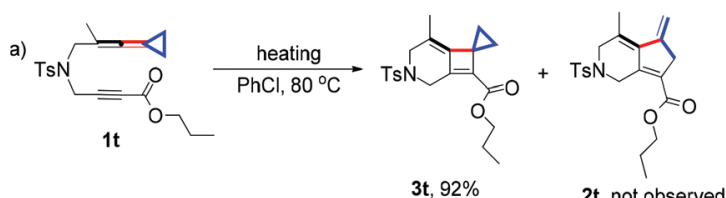

b)
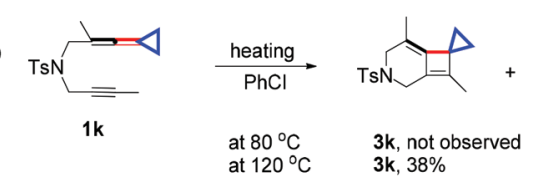

2t, not observed
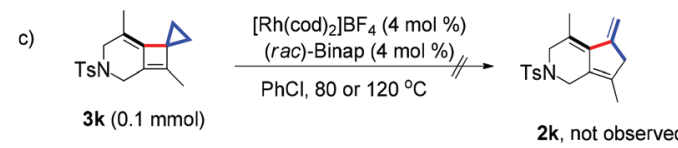

Scheme 2 Control experiments.

exclusively obtained in $41 \%$ yield if using 1,2-dichloroethane (DCE) as the solvent. All these results indicated a broad substrate scope for this Rh(I)-catalyzed synthetic protocol.

Control experiments were conducted to probe the mechanism of this cycloaddition reaction. In the case of $\mathbf{1 t}$, upon heating $1 \mathrm{t}$ at $80^{\circ} \mathrm{C}$ in $\mathrm{PhCl}$ for $12 \mathrm{~h}$ in the absence of the cationic Rh(I) catalyst, product 3t could be obtained in $92 \%$ yield without formation of product $\mathbf{2 t}$ (Scheme $2 \mathrm{a}$ ). For substrate $\mathbf{1 k}$, although none of the $[2+2]$ cycloadduct $3 \mathbf{k}$ could be detected at $80{ }^{\circ} \mathrm{C}, 38 \%$ yield of $3 \mathbf{k}$ could be afforded upon heating at $120{ }^{\circ} \mathrm{C}$ in $\mathrm{PhCl}$ for $48 \mathrm{~h}$ also without formation of $\mathbf{2 k}$ (Scheme 2b). Furthermore, treating 3k under the standard conditions did not give the corresponding $[3+2]$ cycloadduct $\mathbf{2 k}$ even if carrying out the reaction at $120{ }^{\circ} \mathrm{C}$ (Scheme 2c). This result suggested that the cyclobutene moiety could not undergo oxidative addition with the cationic Rh(I) complex, although the oxidative addition to cyclobutenones could take place smoothly. ${ }^{12}$ Therefore, the initial oxidative addition of yne-VDCP 1 to give intermediate $\mathbf{I}-\mathbf{3}$ is essential in this Rh(I)catalyzed transformation (Scheme 1c).

Further transformations of the present product 2 were also examined briefly. The hydrogenation of $\mathbf{2} \mathbf{d}$ and $\mathbf{2 k}$ in methanol under $\mathrm{H}_{2}$ atmosphere in the presence of $\mathrm{Pd} / \mathrm{C}$ could give the corresponding products $\mathbf{4}$ and $\mathbf{5}$ in $61 \%$ and $72 \%$ yields, respectively (Scheme 3).

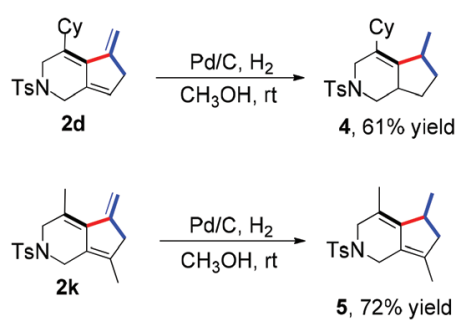

Scheme 3 The further transformation of products 2 . 


\section{Conclusions}

In conclusion, we have developed a novel $\mathrm{Rh}(\mathrm{I})$-catalyzed intramolecular $[3+2]$ cycloaddition of yne-VDCP substrates, giving the corresponding fused [6.5]-bicyclic products in good yields under mild conditions. The substrate scope is broad along with good functional group tolerance allowing the easy generation of various carbo- and heterobicyclic compounds under mild conditions. This $\mathrm{Rh}(\mathrm{I})$-catalyzed synthetic strategy significantly extended the substrate scope for the construction of bicyclic derivatives as compared with those of gold(I)-catalyzed cycloisomerizations.${ }^{8 j}$ Additional efforts on the investigation of the mechanistic details of this intramolecular $[3+2]$ cycloaddition reaction and application of this protocol to the synthesis of biologically active substances are currently ongoing in our laboratory.

\section{Experimental section}

\section{General experimental methods}

Melting points were determined on a digital melting point apparatus and temperatures were uncorrected. NMR spectra were recorded with a Bruker spectrometer at $400 \mathrm{MHz}$ $\left({ }^{1} \mathrm{H} \mathrm{NMR}\right)$, and $100 \mathrm{MHz}\left({ }^{13} \mathrm{C} \mathrm{NMR}\right)$ in $\mathrm{CDCl}_{3}$, respectively. Chemical shifts were reported in ppm downfield from internal TMS. Organic solvents used were dried by standard methods when necessary. Commercially available reagents were used without further purification. All reactions were monitored by TLC with Huanghai GF254 silica gel coated plates. Flash column chromatography was carried out using 300-400 mesh silica gel at increased pressure. Infrared spectra were recorded on a PerkinElmer PE-983 spectrometer with absorption in $\mathrm{cm}^{-1}$. Mass spectra were recorded by ESI and HRMS was measured on an HP-5989 instrument.

\section{General procedure for the synthesis of 2}

A $10 \mathrm{~mL}$ dried tube was charged with yne-VDCP $1(0.1 \mathrm{mmol}$, 1.0 equiv.), $\left[\mathrm{Rh}(\mathrm{cod})_{2}\right] \mathrm{BF}_{4} \quad\left(\begin{array}{lll}4.0 & \mathrm{~mol} \%)\end{array}\right)$ and (rac)-Binap (4.0 mol\%). The reaction tube was evacuated and backfilled with argon (repeated three times). Then, $\mathrm{PhCl}(2.0 \mathrm{~mL})$ was added into the tube. The reaction mixture was stirred at $80{ }^{\circ} \mathrm{C}$ for 6-8 $\mathrm{h}$. The solvent was removed under reduced pressure and the residue was purified by flash column chromatography $\left(\mathrm{SiO}_{2}\right)$ to give the corresponding product 2 .

4-Methyl-5-methylene-7-pentyl-2-tosyl-2,3,5,6-tetrahydro- $1 \mathrm{H}$ cyclopenta[c]pyridine (21). A light yellow oil, $84 \%$ yield (31 mg). ${ }^{1} \mathrm{H}$ NMR (400 MHz, $\left.\mathrm{CDCl}_{3}, \mathrm{TMS}\right) \delta 7.63(\mathrm{~d}, J=8.4 \mathrm{~Hz}$, $2 \mathrm{H}), 7.24(\mathrm{~d}, J=8.0 \mathrm{~Hz}, 2 \mathrm{H}), 5.16(\mathrm{~s}, 1 \mathrm{H}), 5.06(\mathrm{~s}, 1 \mathrm{H}), 3.94(\mathrm{~s}$, $2 \mathrm{H}), 3.75(\mathrm{~s}, 2 \mathrm{H}), 2.95(\mathrm{~s}, 2 \mathrm{H}), 2.38(\mathrm{~s}, 3 \mathrm{H}), 2.12(\mathrm{t}, J=8.0 \mathrm{~Hz}$, $2 \mathrm{H}), 1.82(\mathrm{~s}, 3 \mathrm{H}), 1.22-1.41(\mathrm{~m}, 6 \mathrm{H}), 0.89(\mathrm{t}, J=7.6 \mathrm{~Hz}, 3 \mathrm{H})$; ${ }^{13} \mathrm{C}$ NMR (100 MHz, $\mathrm{CDCl}_{3}$, TMS) $\delta 145.0,143.4,137.5,135.1$, 134.0, 129.4, 129.2, 127.6, 119.9, 109.0, 50.2, 43.3, 41.5, 31.7, 28.3, 27.5, 22.5, 21.4, 17.4, 14.0; IR $\left(\mathrm{CH}_{2} \mathrm{Cl}_{2}\right): \nu$ 3022, 2938, 2813, 1659, 1547, 1402, 1282, 1174, 1058, 917, 947, 819, 759,
721, $630 \mathrm{~cm}^{-1}$; HRMS (ESI) calcd for $\mathrm{C}_{22} \mathrm{H}_{30} \mathrm{NO}_{2} \mathrm{~S}(\mathrm{M}+\mathrm{H})^{+}$ requires: 372.1992 , Found: 372.1985 .

\section{Conflicts of interest}

There are no conflicts of interest to declare.

\section{Acknowledgements}

We are grateful for the financial support from the National Basic Research Program of China [(973)-2015CB856603], the Strategic Priority Research Program of the Chinese Academy of Sciences (Grant No. XDB20000000 and sioczz201808), the National Natural Science Foundation of China (20472096, 21372241, 21572052, 20672127, 21421091, 21372250, 21121062, 21302203, 21772037, 21772226, 20732008, 21772037, 21772226 and 21861132014), and the Fundamental Research Funds for the Central Universities 222201717003.

\section{Notes and references}

1 (a) Y. Kavanagh, M. O'Brien and P. Evans, Tetrahedron, 2009, 65, 8259; (b) K. Takeda and M. Toyota, Tetrahedron, 2011, 67, 9909; (c) A.-C. Guevel and D. J. Hart, J. Org. Chem., 1996, 61, 473; (d) Y.-L. Kuo, M. Dhanasekaran and C.-K. Sha, J. Org. Chem., 2009, 74, 2033; (e) K. Takahashi, K. Takeda and T. Honda, Tetrahedron Lett., 2010, 51, 3542; (f) J. S. Beckett, J. D. Beckett and J. E. Hofferberth, Org. Lett., 2010, 12, 1408.

2 For selected reviews, see: (a) J. A. Varela and C. Saa, Chem. Rev., 2003, 103, 3787; (b) K. Tanaka, Synlett, 2007, 1977; (c) T. Shibata and K. Tsuchikama, Org. Biomol. Chem., 2008, 6, 1317; (d) S. Perreault and T. Rovis, Chem. Soc. Rev., 2009, 38, 3149; (e) M. Murakami and T. Matsuda, Chem. Commun., 2011, 47, 1100; (f) C. Aissa, Synthesis, 2011, 3389; $(g)$ L. Souillart and N. Cramer, Chem. Rev., 2015, 115, 9410; (h) P.-H. Chen, B. A. Billett, T. Tsukamoto and G. Dong, ACS Catal., 2017, 7, 1340; (i) G. Chen, X. Jiang, C. Fu and S. Ma, Chem. Lett., 2010, 39, 78; (j) C. Aubert, L. Fensterbank, P. Garcia, M. Malacria and A. Simonneau, Chem. Rev., 2011, 111, 1954.

3 Recent reviews of MCPs, see: (a) M. Rubin, M. Rubina and V. Gevorgyan, Chem. Rev., 2007, 107, 3117; (b) I. Nakamura and Y. Yamamoto, Adv. Synth. Catal., 2002, 344, 111; (c) A. Brandi, S. Cicchi, F. M. Cordero and A. Goti, Chem. Rev., 2003, 103, 1213; (d) L.-X. Shao and M. Shi, Curr. Org. Chem., 2007, 11, 1135; (e) H. Pellissier, Tetrahedron, 2010, 66, 8341; (f) G. Audran and H. Pellissier, Adv. Synth. Catal., 2010, 352, 575; (g) A. Masarwa and I. Marek, Chem. - Eur. J., 2010, 16, 9712; (h) L. Yu and R. Guo, Org. Prep. Proced. Int., 2011, 43, 209; (i) M. Shi, J.-M. Lu, Y. Wei and L.-X. Shao, Acc. Chem. Res., 2012, 45, 641; $(j)$ A. Brandi, S. Cicchi, F. M. Cordero and A. Goti, Chem. Rev., 2014, 114, 7317; ( $k$ ) H. Pellissier, Tetrahedron, 2014, 70, 4991; (l) L. Yu, 
M. Liu, F. Chen and Q. Xu, Org. Biomol. Chem., 2015, 13, 8379.

4 For some more recent papers related to MCPs, please see: (a) A. Fürstner and C. Aïssa, J. Am. Chem. Soc., 2006, 128, 6306; (b) M. Shi, L.-P. Liu and J. Tang, J. Am. Chem. Soc., 2006, 128, 7430; (c) C. Aïssa and A. Fürstner, J. Am. Chem. Soc., 2007, 129, 14836; (d) S. Simaan and I. Marek, J. Am. Chem. Soc., 2010, 132, 4066; (e) K. Chen, M. Jiang, Z. Zhang, Y. Wei and M. Shi, Eur. J. Org. Chem., 2011, 7189; $(f)$ S. Cui, Y. Zhang and Q. Wu, Chem. Sci., 2013, 4, 3421; (g) J. C. Timmerman, B. D. Robertson and R. A. Widenhoefer, Angew. Chem., Int. Ed., 2015, 54, 2251; (h) Z.-Z. Zhu, K. Chen, L.-Z. Yu, X.-Y. Tang and M. Shi, Org. Lett., 2015, 17, 5994; (i) B. Yao, Y. Li, Z. Liang and Y. Zhang, Org. Lett., 2011, 13, 640; (j) K. Chen, Z.-Z. Zhu, Y.-S. Zhang, X.-Y. Tang and M. Shi, Angew. Chem., Int. Ed., 2014, 53, 6645; (k) K. Chen, Z.-Z. Zhu, J.-X. Liu, X.-Y. Tang, Y. Wei and M. Shi, Chem. Commun., 2016, 52, 350; (l) M. Araya, M. Gulías, I. Fernández, G. Bhargava, L. Castedo, J. L. Mascareñas and F. López, Chem. - Eur. J., 2014, 20, 10255; ( $m$ ) D.-H. Zhang, X.-Y. Tang, Y. Wei and M. Shi, Chem. - Eur. J., 2013, 19, 13668; (n) D.-H. Zhang, Y. Wei and M. Shi, Chem. - Eur. J., 2012, 18, 7026; (o) B. Cao, Y. Wei and M. Shi, Chem. Commun., 2018, 54, 14085.

5 Recent reviews of VCPs, see: (a) Y. Wang and Z.-X. Yu, Acc. Chem. Res., 2015, 48, 2288; (b) Z.-X. Yu, Y. Wang and Y. Wang, Chem. - Asian J., 2010, 5, 1072; (c) D. K. Brownsey, E. Gorobets and D. J. Derksen, Org. Biomol. Chem., 2018, 16, 3506; (d) M. Meazza, H. Guo and R. Rios, Org. Biomol. Chem., 2017, 15, 2479; (e) V. Ganesh and S. Chandrasekaran, Synthesis, 2016, 48, 4347; $(f)$ J. E. Baldwin, Chem. Rev., 2003, 103, 1197; $(g)$ T. Sato, K. Izawa, J. L. Aceña, H. Liu and V. A. Soloshonok, Eur. J. Org. Chem., 2016, 2757.

6 For some more recent papers related to VCPs, please see: (a) P. A. Wender, C. O. Husfeld, E. Langkopf and J. A. Love, J. Am. Chem. Soc., 1998, 120, 1940; (b) P. A. Wender, A. J. Dyckman, C. O. Husfeld, D. Kadereit, J. A. Love and H. Rieck, J. Am. Chem. Soc., 1999, 121, 10442; (c) P. A. Wender and T. J. Williams, Angew. Chem., Int. Ed., 2002, 41, 4550; (d) P. A. Wender, A. B. Lesser and L. E. Sirois, Angew. Chem., Int. Ed., 2012, 51, 2736; (e) P. A. Wender, L. O. Haustedt, J. Lim, J. A. Love, T. J. Williams and J. Y. Yoon, J. Am. Chem. Soc., 2006, 128, 6302; $(f)$ R. Shintani, H. Nakatsu, K. Takatsu and T. Hayashi, Chem. - Eur. J., 2009, 15, 8692; (g) F. Inagaki, K. Sugikubo, Y. Miyashita and C. Mukai, Angew. Chem., Int. Ed., 2010, 49, 2206; (h) K. Sugikubo, F. Omachi, Y. Miyanaga, F. Inagaki, C. Matsumoto and C. Mukai, Angew. Chem., Int. Ed., 2013, 52, 11369; (i) C. H. Liu and
Z. X. Yu, Angew. Chem., Int. Ed., 2017, 56, 8667; (j) X. Hong, M. C. Stevens, P. Liu, P. A. Wender and K. N. Houk, J. Am. Chem. Soc., 2014, 136, 17273; (k) P. Liu, L. E. Sirois, P. H. Y. Cheong, Z. X. Yu, I. V. Hartung, H. Rieck, P. A. Wender and K. N. Houk, J. Am. Chem. Soc., 2010, 132, 10127; (l) P. A. Wender, D. N. Fournogerakis, M. S. Jeffreys, R. V. Quiroz, F. Inagaki and M. Pfaffenbach, Nat. Chem., 2014, 6, 448; (m) L. Jiao, C. X. Yuan and Z. X. Yu, J. Am. Chem. Soc., 2008, 130, 4421; (n) L. Jiao, M. Lin and Z. X. Yu, J. Am. Chem. Soc., 2011, 133, 447; (o) D.-H. Liu and Z.-X. Yu, Synlett, 2018, 29, 764.

7 Recent reviews of VDCPs, see: (a) M. Shi, L.-X. Shao, J.-M. Lu, Y. Wei, K. Mizuno and H. Maeda, Chem. Rev., 2010, 110, 5883; (b) B.-L. Lu, L.-Z. Dai and M. Shi, Chem. Soc. Rev., 2012, 41, 3318; (c) D.-H. Zhang, X.-Y. Tang and M. Shi, Acc. Chem. Res., 2014, 47, 913; (d) S. Yang and M. Shi, Acc. Chem. Res., 2018, 51, 1667.

8 For some more recent papers related to VDCPs, please see: (a) S. Yang, K.-H. Rui, X.-Y. Tang, Q. Xu and M. Shi, J. Am. Chem. Soc., 2017, 139, 5957; (b) S. Yang, Q.-Z. Li, C. Xu, Q. Xu and M. Shi, Chem. Sci., 2018, 9, 5074; (c) S. Yang, Q. Xu and M. Shi, Chem. - Eur. J., 2016, 22, 10387; (d) S. Yang, W. Yuan, Q. Xu and M. Shi, Chem. - Eur. J., 2015, 21, 15964; (e) D.-Y. Li, Y. Wei, I. Marek, X.-Y. Tang and M. Shi, Chem. Sci., 2015, 6, 5519; $(f)$ A. V. Stepakov, A. G. Larina, V. M. Boitsov, V. V. Gurzhiy, A. P. Molchanov and R. R. Kostikov, Tetrahedron Lett., 2014, 55, 2022; (g) M.-Z. Miao, J. Cao, J.-J. Zhang, X. Huang and L.-L. Wu, J. Org. Chem., 2013, 78, 2687; (h) N. U. Zhanpeisov, K. Mizuno, M. Anpo and J. Leszczynski, Int. J. Quantum Chem., 2004, 96, 343; (i) H. Maeda, T. Hirai, A. Sugimoto and K. Mizuno, J. Org. Chem., 2003, 68, 7700; (j) W. Yuan, X. Tang, Y. Wei and M. Shi, Chem. - Eur. J., 2014, 20, 3198.

9 B.-L. Lu and M. Shi, Angew. Chem., Int. Ed., 2011, 50, 12027. 10 W. Yuan, X. Dong, M. Shi, P. McDowell and G.-G. Li, Org. Lett., 2012, 14, 5582.

11 For selected examples related to thermal induced cyclizations, see: (a) S. Yang, Q. Xu and M. Shi, Tetrahedron, 2016, 72, 584; (b) I. Nakamura, T. Nemoto, Y. Yamamoto and A. de Meijere, Angew. Chem., Int. Ed., 2006, 45, 5176; (c) I. Nakamura, R. Nagata, T. Nemoto, M. Terada, Y. Yamamoto, T. Späth and A. de Meijere, Eur. J. Org. Chem., 2007, 4479; (d) X.-Y. Tang and M. Shi, J. Org. Chem., 2009, 74, 5983.

12 (a) M. A. Huffman, L. S. Liebeskind and W. T. Pennington, Organometallics, 1990, 9, 2194; (b) M. A. Huffman, L. S. Liebeskind and W. T. Pennington, Organometallics, 1992, 11, 255; (c) T. Xu, H. M. Ko, N. A. Savage and G. Dong, J. Am. Chem. Soc., 2012, 134, 20005; (d) M. A. Huffman and L. S. Liebeskind, J. Am. Chem. Soc., 1991, 113, 2771. 